Check for updates

Cite this: Mater. Adv., 2021, 2,6684

Received 17th August 2021,

Accepted 2nd September 2021

DOI: $10.1039 / \mathrm{d} 1 \mathrm{ma} 00738 f$

rsc.li/materials-advances

\section{Electron-withdrawing group modified carbazolophane donors for deep blue thermally activated delayed fluorescence OLEDs $\dagger$}

\author{
Abhishek Kumar Gupta, (D) $\ddagger^{\text {ab }}$ Zhen Zhang, $\ddagger^{c}$ Eduard Spuling, ${ }^{\text {ac }}$ Maria Kaczmarek, ${ }^{c}$ \\ Yichuan Wang, ${ }^{\mathrm{C}}$ Zahid Hassan, (D) ${ }^{\mathrm{C}}$ Ifor D. W. Samuel, (D) *b Stefan Bräse*cd and \\ Eli Zysman-Colman (D)*a
}

\begin{abstract}
We report two blue-emitting thermally activated delayed fluorescence (TADF) compounds employing a substituted carbazolophane (Czp) donor (indolo[2.2]paracyclophane). The compounds CNCzpPhTRZ and CF $_{3}$ CzpPhTRZ show emission maxima of $426 \mathrm{~nm}$ and $432 \mathrm{~nm}$, respectively, with high photoluminescence quantum yields $\left(\Phi_{\mathrm{PL}}\right)$ of $73 \%$ and $80 \%$, respectively. The singlet-triplet energy gap $\left(\Delta E_{\mathrm{ST}}\right)$ of both emitters is $0.22 \mathrm{eV}$, resulting in long-delayed lifetimes of $132 \mu \mathrm{s}$ for CNCzpPhTRZ and $158 \mu$ s for $\mathrm{CF}_{3}$ CzpPhTRZ in PPT as the host matrix. Blue organic light-emitting diodes (OLEDs) showed

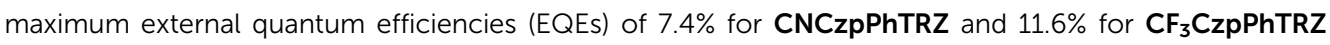
with electroluminescence maxima of ca. $460 \mathrm{~nm}$.
\end{abstract}

\section{Introduction}

The development of purely organic thermally activated delayed fluorescence (TADF) emitters is considered as one of the most promising approaches to utilize singlet and triplet excitons to access highly efficient organic light-emitting diodes (OLEDs). ${ }^{1-4}$ The design principle of generating a structure with spatially separated donor and acceptor moieties to limit the exchange integral between the highest occupied molecular orbital (HOMO) and the lowest unoccupied molecular orbital (LUMO) thereby leading to a small singlet and triplet excited state energy difference, $\Delta E_{\mathrm{ST}}$, has been a reliable and fruitful strategy to construct TADF emitters. To obtain a small $\Delta E_{\mathrm{ST}}$, there are at present at least six design strategies, which are twisted donoracceptor, ${ }^{1}$ multi-resonance, ${ }^{5}$ spiro-conjugation, ${ }^{6}$ exciplex, ${ }^{7}$

\footnotetext{
${ }^{a}$ Organic Semiconductor Centre, EaStCHEM School of Chemistry,

University of St Andrews, St Andrews, Fife, KY16 9ST, UK

E-mail: eli.zysman-colman@st-andrews.ac.uk

${ }^{b}$ Organic Semiconductor Centre, SUPA, School of Physics and Astronomy,

University of St Andrews, North Haugh, St Andrews, KY16 9SS, UK.

E-mail: idws@st-andrews.ac.uk

${ }^{c}$ Institute of Organic Chemistry, Karlsruhe Institute of Technology (KIT), Fritz-Haber-Weg 6, 76131, Karlsruhe, Germany. E-mail: braese@kit.edu

${ }^{d}$ Institute of Biological and Chemical Systems - Functional Molecular Systems (IBCS-FMS), Karlsruhe Institute of Technology (KIT),

Hermann-von-Helmholtz-Platz 1, D-76344, Eggenstein-Leopoldshafen, Germany

$\dagger$ Electronic supplementary information (ESI) available: The research data supporting this publication can be accessed at DOI: $10.17630 / 8$ cbdf064-a1c6-482fbf7e-77d93ccf516f. See DOI: 10.1039/d1ma00738f

\$ Abhishek Kumar Gupta and Zhen Zhang contributed equally to this work.
}

excited-state intramolecular proton transfer $\left(\right.$ ESIPT) ${ }^{8}$ and through space-conjugation. ${ }^{9}$ The most popular of these is to electronically decouple the donor and acceptor by ensuring a highly twisted conformation.

The [2.2]paracyclophane (PCP) is a rigid molecule containing two slightly bent benzene rings connected by ethylene bridges. Due to the spatial stacked configuration and a short distance of 2.78-3.09 A between the two benzene decks, which is smaller than the van der Waals distance between the layers of graphite (3.35 ̊), a strong transannular electronic communication can take place, as demonstrated by Bazan et al. ${ }^{10-14}$ Substituted PCPs can possess planar charity and emissive analogs can exhibit circularly polarized luminescence (CPL) ${ }^{15}$ The characteristics of rigid skeleton, chemical and photo stability, planar charity, and through-space electronic communication possessed by the PCP core make it a potentially useful building block for organic semiconductor materials.

In 2018, we first demonstrated that the PCP moiety could be used to mediate weak electronic communication between donor and acceptor groups on different decks of the PCP. ${ }^{9}$ Trans-Bz-PCP-TPA and cis-Bz-PCP-TPA showed photoluminescence maxima, $\lambda_{\mathrm{PL}}$, at $455 \mathrm{~nm}$, photoluminescence quantum yields, $\Phi_{\mathrm{PL}}$, of $60 \%$ (in toluene), $\Delta E_{\mathrm{ST}}=0.19 \mathrm{eV}$ and delayed lifetime, $\tau_{\mathrm{d}}$, of $3.6 \mu \mathrm{s}$ for trans-Bz-PCP-TPA and $\lambda_{\mathrm{PL}}$ of $492 \mathrm{~nm}$, $\Phi_{\mathrm{PL}}$ of $45 \%$ (in toluene), $\Delta E_{\mathrm{ST}}=0.04 \mathrm{eV}$ and $\tau_{\mathrm{d}}$ of $1.8 \mu \mathrm{s}$ for cisBz-PCP-TPA in $15 \mathrm{wt} \% \mathrm{mCP}$ doped film (Fig. 1). Zhao et al. also reported a series of structurally similar chiral green TADF molecules $\boldsymbol{g}$-BNMe-Cp and $\boldsymbol{m}$-BNMe-Cp containing a PCP, with emission at $531 \mathrm{~nm}\left(\Phi_{\mathrm{PL}}=72 \%\right.$ in cyclohexane, $\Delta E_{\mathrm{ST}}=0.17 \mathrm{eV}$ 


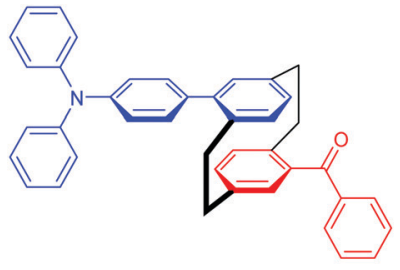

trans-Bz-PCP-TPA

$\Delta E_{\mathrm{ST}}=0.19 \mathrm{eV}, \lambda_{\mathrm{PL}}=455 \mathrm{~nm}$ in toluene $\Phi_{\mathrm{PL}}=0.60$ in toluene $\tau_{d}=3.6 \mu \mathrm{s}$ in $15 \mathrm{wt} \% \mathrm{mCP}$ doped film Chem. Commun. 2018, 54, 9278.

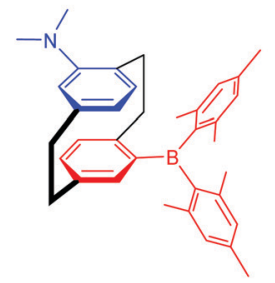

m-BNMe ${ }_{2}-\mathrm{Cp}$

$\Delta E_{\mathrm{ST}}=0.12 \mathrm{eV}, \lambda_{\mathrm{PL}}=521 \mathrm{~nm}$ in toluene $\Phi_{\mathrm{PL}}=0.39$ in cyclohexane $\tau_{\mathrm{d}}=0.22 \mu \mathrm{s}$ in toluene Org. Lett. 2018, 20, 6868.

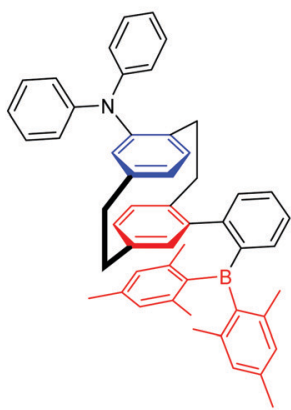

$m-\mathrm{BPhNPh}_{2}-\mathrm{Cp}$

$\Delta E_{\mathrm{ST}}=0.17 \mathrm{eV}, \lambda_{\mathrm{PL}}=464 \mathrm{~nm}$ in toluene $\Phi_{\mathrm{PL}}=0.82$ in cyclohexane, Org. Lett. 2021, 23, 2.

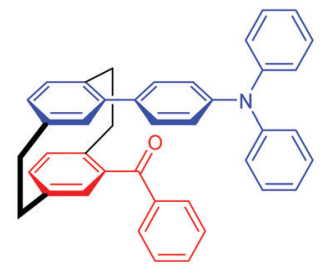

cis-Bz-PCP-TPA

$\Delta E_{\mathrm{ST}}=0.04 \mathrm{eV}, \lambda_{\mathrm{PL}}=492 \mathrm{~nm}$ in toluene $\Phi_{\mathrm{PL}}=0.45$ in toluene $\tau_{d}=1.8 \mu$ in $15 \mathrm{wt} \%$ mCP doped film Chem. Commun. 2018, 54, 9278.

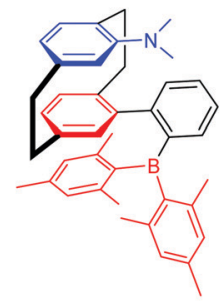

$g$-BPhNMe ${ }_{2}-\mathrm{Cp}$

$\Delta E_{\mathrm{ST}}=0.17 \mathrm{eV}, \lambda_{\mathrm{PL}}=510 \mathrm{~nm}$ in toluene $\Phi_{\mathrm{PL}}=0.83$ in cyclohexane, Org. Lett. 2021, 23, 2.

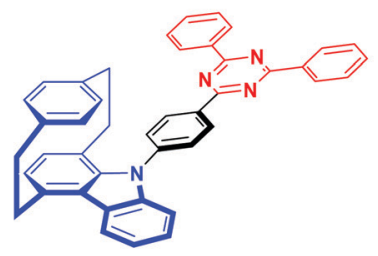

CzpPhTrz

$\Delta E_{\mathrm{ST}}=0.30 \mathrm{eV}, \lambda_{\mathrm{PL}}=470 \mathrm{~nm}$ in toluene $\Phi_{P L}=0.70$ in toluene $\tau_{\mathrm{d}}=65 \mu \mathrm{s}$ in $10 \mathrm{wt} \%$ DPEPO doped film $\lambda_{\mathrm{EL}}=480 \mathrm{~nm}$ in $10 \mathrm{wt} \%$ DPEPO doped film $\mathrm{CIE}(0.17,0.25), \mathrm{EQE}_{\max }: 17.0 \%$ Chem Sci. $2019,10,6689$

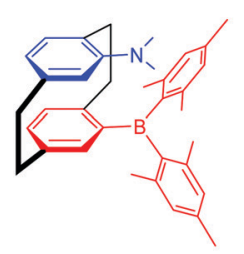

g-BNMe2-Cp

$\Delta E_{\mathrm{ST}}=0.17 \mathrm{eV}, \lambda_{\mathrm{PL}}=531 \mathrm{~nm}$ in toluene

$\Phi_{\mathrm{PL}}=0.72$ in cyclohexane

$\tau_{\mathrm{d}}=0.38 \mu$ s in toluene

Org. Lett. 2018, 20, 6868.

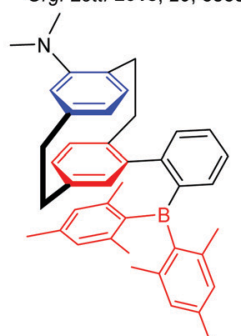

$m-\mathrm{BPhNMe}_{2}-\mathrm{Cp}$

$\Delta E_{\mathrm{ST}}=0.17 \mathrm{eV}, \lambda_{\mathrm{PL}}=481 \mathrm{~nm}$ in toluene

$\Phi_{\mathrm{PL}}=0.92$ in cyclohexane, -

Org. Lett. 2021, 23, 2.

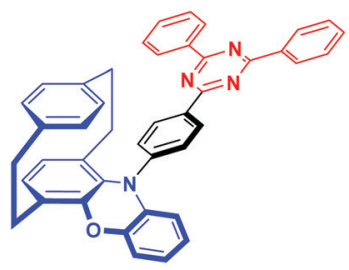

PXZp-Ph-TRZ

$\Delta E_{\mathrm{ST}}=0.03 \mathrm{eV}, \lambda_{\mathrm{PL}}=548 \mathrm{~nm}$ in toluene $\Phi_{P L}=0.60$ in $10 w t \%$ CBP doped film $\tau_{d}=12.1 \mu \mathrm{s}$ in $10 \mathrm{wt} \%$ CBP doped film $\lambda_{\mathrm{EL}}=560 \mathrm{~nm}$ in $10 \mathrm{wt} \% \mathrm{CBP}$ doped film $\mathrm{CIE}(0.49,0.50), \mathrm{EQE}_{\max }: 7.8 \%$ ACS Appl. Mater. Interfaces DOI: 10.1021/acsami.1c04779

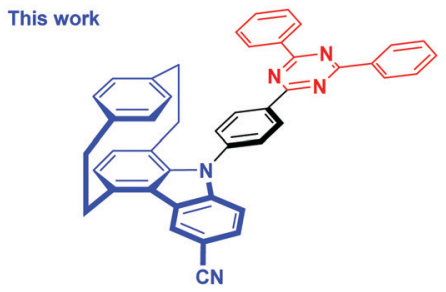

$$
\begin{aligned}
& \text { CNCzpPhTRZ } \\
& \Delta E_{\mathrm{ST}}=0.22 \mathrm{eV}, \lambda_{\mathrm{PL}}=426 \mathrm{~nm} \text { in toluene } \\
& \Phi_{\mathrm{PL}}=0.73 \text { in toluene } \\
& \tau_{\mathrm{p}}=135.0 \mu \mathrm{s} 10 \mathrm{wt} \% \text { PPT doped film } \\
& \lambda_{\mathrm{EL}}=458 \mathrm{~nm} \text { in } 10 \mathrm{wt} \% \text { PPT doped film }
\end{aligned}
$$$$
\text { CIE }(0.19,0.18), E \text { : } 7.4 \%
$$

Fig. 1 Chemical structures and performance of PCP-based TADF molecules.

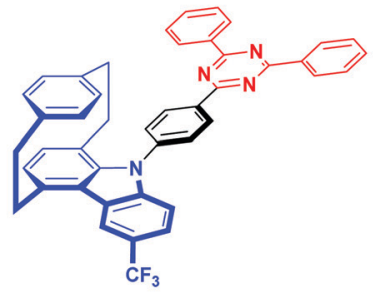

$\mathrm{CF}_{3} \mathrm{CzpPhTRZ}$

$\Delta E_{\mathrm{ST}}=0.22 \mathrm{eV}, \lambda_{\mathrm{PL}}=426 \mathrm{~nm}$ in toluene

$\Phi_{\mathrm{PL}}=0.80$ in toluene

$\tau_{d}=151.4 \mu$ s in $10 w t \%$ PPT doped film

$\lambda_{E L}=456 \mathrm{~nm}$ in 10 wt $\%$ PPT doped film

$\operatorname{CIE}(0.19,0.20), \mathrm{EQE}_{\max }: 11.6 \%$ and $\tau_{\mathrm{d}}=0.38 \mu \mathrm{s}$ in toluene $)$ and $521 \mathrm{~nm}\left(\Phi_{\mathrm{PL}}=39 \%\right.$ in cyclohexane, $\Delta E_{\mathrm{ST}}=0.12 \mathrm{eV}$ and $\tau_{\mathrm{d}}=0.22 \mu \mathrm{s}$ in toluene), respectively (Fig. 1). ${ }^{16}$ Recently, the same group introduced a phenylene spacer between the PCP and the acceptor moiety to obtain sky-blue to green TADF emitters showing increased $\Phi_{\mathrm{PL}}$ (in cyclohexane) to $83 \%$ for $\boldsymbol{g}$-BPhNMe 2 -Cp, 93\% for $\boldsymbol{m}$-BPhNMe $\mathbf{B P}_{2}-\mathbf{C p}$, and $82 \%$ for $\boldsymbol{g}$-BPhNPh $\mathbf{H}_{\mathbf{2}}$-Cp (Fig. 1). ${ }^{17}$ Besides using the PCP as a bridge motif to enable electronic coupling between donor and acceptor groups, we also demonstrated how the PCP skeleton could be incorporated within the carbazole donor unit. Carbazolophane 


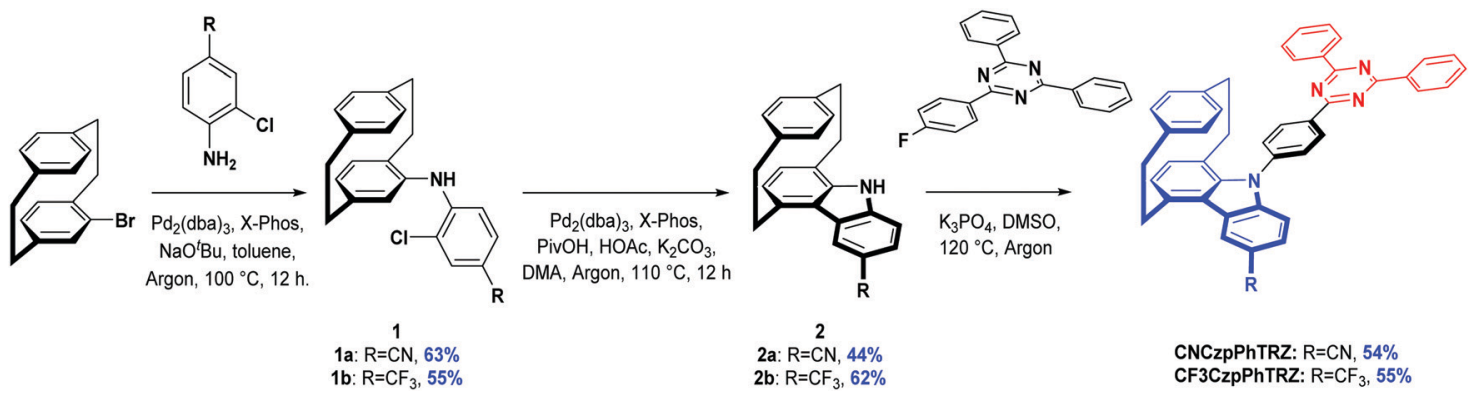

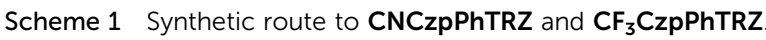

(Czp, [2]paracyclo[2](1,4)carbazolophane) group is a stronger electron donor that adopts a more twisted conformation due to its greater steric bulk. ${ }^{9}$ We reported the chiral TADF emitter CzpPhTRZ, which showed a small $\Delta E_{\mathrm{ST}}$ of $0.16 \mathrm{eV}$, and $\lambda_{\mathrm{PL}}$ at $482 \mathrm{~nm}$ with $\Phi_{\mathrm{PL}}=69 \%$ and a $\tau_{\mathrm{d}}$ of $65 \mu \mathrm{s}$ in $10 \mathrm{wt} \%$ DPEPO doped film. ${ }^{18}$ Sky-blue OLEDs with CzpPhTRZ showed a maximum external quantum efficiency $\left(\mathrm{EQE}_{\max }\right)$ of $17.0 \%$ and CIE coordinates of $(0.17,0.25)$. Zheng and co-workers reported an analog of CzpPhTRZ, PXZp-Ph-TRZ, where the Czp donor was replaced with a phenoxazinephane (PXZp). PXZp-Ph-TRZ possesses a $\Delta E_{\mathrm{ST}}$ of $0.03 \mathrm{eV}$ and shows yellow emission with $\lambda_{\mathrm{PL}}$ at $560 \mathrm{~nm}$ in $10 \mathrm{wt} \% \mathrm{CBP}$ doped film. The OLED showed an $\mathrm{EQE}_{\max }$ of $7.8 \%$ and CIE coordinates of $(0.49$, 0.50). ${ }^{19}$ As we can see from Fig. 1 since our first report, a handful of emitters have been reported containing the PCP moiety; however none to date show pure blue emission.

Building on our prior work and with the goal to obtain a blueshifted emission, we designed two new TADF emitters CNCzpPhTRZ

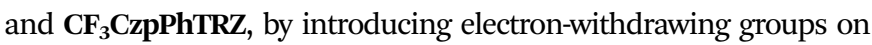
the Czp donor unit of the parent CzpPhTRZ emitter. We successfully blue-shifted the emission without adversely affecting the TADF efficiency. CNCzpPhTRZ emits at $426 \mathrm{~nm}$, and $\mathbf{C F}_{3} \mathbf{C z p P h T R Z}$ emits at $432 \mathrm{~nm}$ in toluene, representing a $c a .40 \mathrm{~nm}$ blue-shift compared to that of CzpPhTRZ. The $\Phi_{\mathrm{PL}}$ remained high at $73 \%$ and $80 \%$, respectively. Further, we fabricated bluer OLEDs with electroluminescence maxima at $c a .460 \mathrm{~nm}$. However, we observed the evolution of a red emission band at around $600 \mathrm{~nm}$ in the OLEDs due to degradation of both blue emitters during the operation of the device.

\section{Results and discussion}

\section{Synthesis and thermal stability}

The synthesis is based on our previously reported route and shown in Scheme 1. Aniline derivatives were coupled to bromo[2.2]paracyclophane with yields of $63 \%$ for 1a, and $55 \%$ for $\mathbf{1 b}$. The generated intermediates were used to form the functionalized carbazolophane donor units with yields of $44 \%$ for $2 \mathrm{a}$ and $62 \%$ for $\mathbf{2 b}$ via a Pd-catalyzed intramolecular oxidative cyclization process where the ortho-chlorine atoms act as the directing group. Lastly, the prepared donor 2 and triazine-based acceptor were linked together via a nucleophilic aromatic substitution with yields above $50 \%$ using tripotassium phosphate as a base in DMSO at $120{ }^{\circ} \mathrm{C}$. The targeted compounds, CNCzpPhTRZ and $\mathbf{C F}_{3}$ CzpPhTRZ, show strong blue luminescence under UV excitation. The identity and purity of CNCzpPhTRZ and $\mathbf{C F}_{3} \mathbf{C z p P h T R Z}$ were determined by a combination of NMR, MS, HRMS, Mp, HPLC and IR.

Differential scanning calorimetry (DSC) and thermogravimetric analysis (TGA) were carried out to explore the thermal stability of the two emitters (Table 1 and Fig. S2, ESI $\dagger$ ). $\mathrm{CF}_{3}$ CzpPhTRZ shows a glass transition temperature $\left(T_{\mathrm{g}}\right)$ of $151{ }^{\circ} \mathrm{C}$ and $5 \%$ weight loss temperature $\left(T_{\mathrm{d} 5}\right)$ of $360{ }^{\circ} \mathrm{C}$. The $T_{\mathrm{g}}$ and $T_{\mathrm{d} 5}$ of CNCzpPhTRZ are higher than those of $\mathrm{CF}_{3} \operatorname{CzpPhTRZ}\left(T_{\mathrm{g}}=184{ }^{\circ} \mathrm{C}\right.$ and $\left.T_{\mathrm{d} 5}=412{ }^{\circ} \mathrm{C}\right)$.

\section{Theoretical calculations}

Density functional theory (DFT) calculations were performed to investigate the frontier orbital densities and energy states of model compounds of the two emitters. The geometries in the ground state of the two emitters were optimized in the gas phase at the PBE0/6-31G(d,p) level of theory. Time-dependent DFT calculations using the Tamm-Dancoff approximation (TDA-DFT) in the gas phase based on the optimized molecular structures provide insight into the energies and nature of the lowest-lying singlet and triplet excited states. ${ }^{20}$ The frontier orbitals and energy levels of these molecules are shown in Fig. 2 and Table S1 (ESI $\dagger$ ).

Table 1 Electrochemical data, HOMO-LUMO, $\Delta E_{\mathrm{ST}}$ and thermal stability data of $\mathrm{CF}_{3} \mathrm{CzpPhTRZ}$ and CNCzpPhTRZ

\begin{tabular}{lllllll}
\hline Emitters & $E_{\mathrm{ox}}{ }^{a} / \mathrm{V}$ & $E_{\mathrm{red}}{ }^{a} / \mathrm{V}$ & $\mathrm{HOMO}^{b} / \mathrm{eV}$ & $\mathrm{LUMO}^{b} / \mathrm{eV}$ & $E_{\mathrm{S}} / E_{\mathrm{T}}{ }^{c} / \mathrm{eV}$ & $\Delta E_{\mathrm{ST}}{ }^{d} / \mathrm{eV}$ \\
\hline $\mathbf{C F}_{3}$ CzpPhTRZ & 1.30 & -1.66 & $-5.64(6.05)$ & -2.68 & $2.91 / 2.69$ & 0.22 \\
CNCzpPhTRZ & 1.34 & -1.67 & $-5.68(5.93)$ & -2.67 & $2.92 / 2.69$ & 0.23
\end{tabular}

${ }^{a} E_{\mathrm{Ox}}$ and $E_{\mathrm{red}}$ are anodic and cathodic peak potentials, respectively, obtained from DPV using $\mathrm{F}_{\mathrm{c}} / \mathrm{F}_{\mathrm{c}}{ }^{+}$as the internal reference and referenced versus $\mathrm{SCE}(0.46 \mathrm{~V} v s$. SCE $)$ in DCM with $0.1 \mathrm{M}\left[n \mathrm{Bu}_{4} \mathrm{~N}\right] \mathrm{PF}_{6}$ as the supporting electrolyte. ${ }^{21}{ }^{1} E_{\mathrm{HOMO} / \mathrm{LUMO}}=-\left(E^{\mathrm{ox}} / E^{\mathrm{red}}+4.8\right) \mathrm{eV},^{22}$ where $E^{\mathrm{Ox}}$ is anodic peak potential and $E^{\text {red }}$ is cathodic peak potential calculated from DPV relative to $\mathrm{F}_{\mathrm{c}} / \mathrm{F}_{\mathrm{c}}{ }^{+}$. Value inside parentheses determined by ambient pressure photoemission spectroscopy (APS). ${ }^{c}$ Obtained from the onset of the prompt fluorescence (time window: 1 ns-100 ns) and phosphorescence spectra (time window: $1 \mathrm{~ms}-10 \mathrm{~ms}$ ) of $10 \mathrm{wt} \%$ samples doped in PPT at $77 \mathrm{~K} .^{d} \Delta E_{\mathrm{ST}}=E_{\mathrm{S}}-E_{\mathrm{T}}$. 


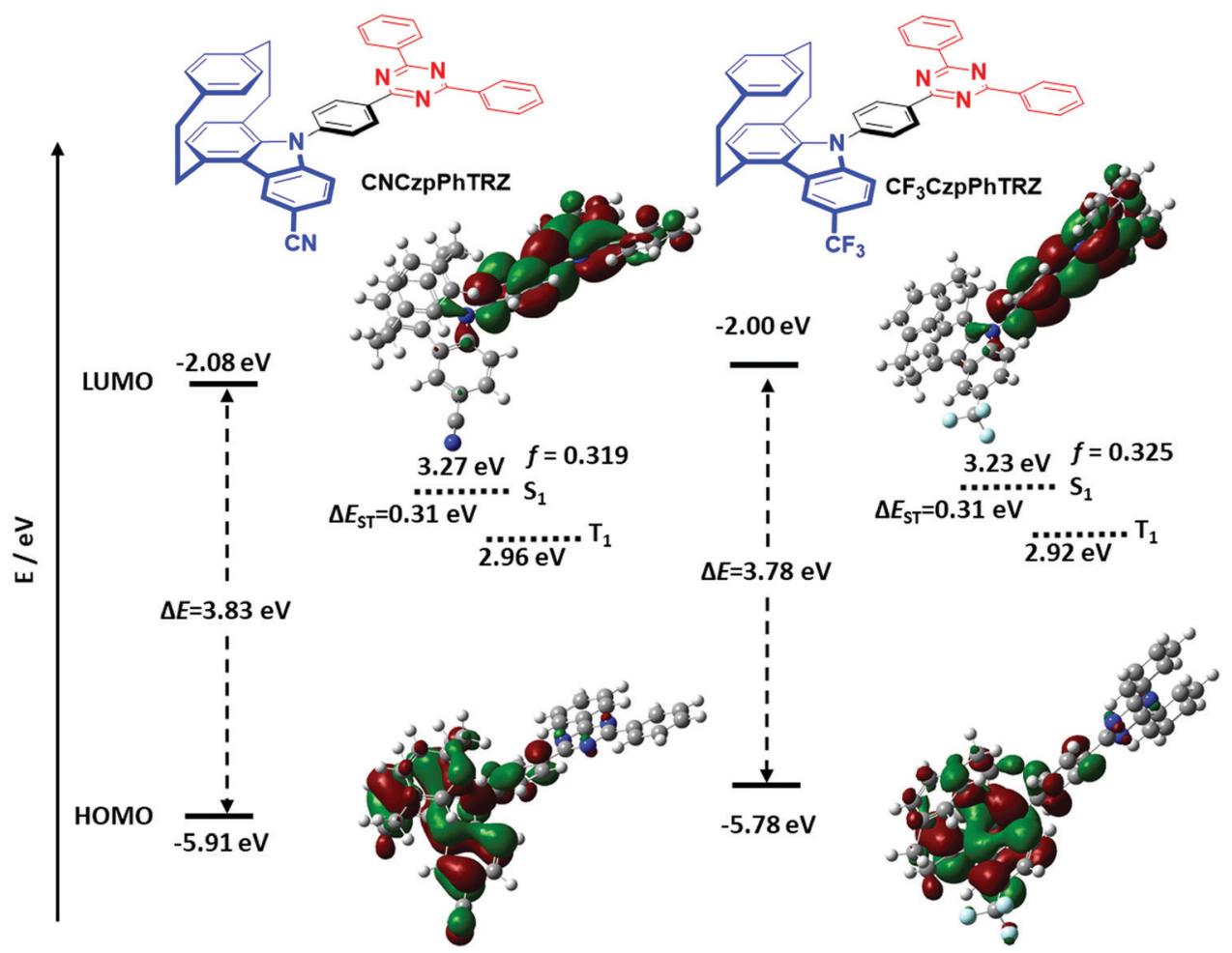

Fig. 2 DFT calculations of CNCzpPhTRZ and $\mathrm{CF}_{3} \mathrm{CzpPhTRZ}$

The torsion angles between the Czp donors and the bridging phenylene are expected not unaffected by the substitution on the distal side of the donor. While for the previously reported CzpPhTRZ, the torsion angle obtained from DFT calculations was $58^{\circ}$, the torsion angles for $\mathbf{C F}_{3} \mathbf{C z p P h T R Z}$ and $\mathbf{C N C z p P h T R Z}$ are $56^{\circ}$ and $58^{\circ}$, respectively. The DFT calculations reveal that the frontier orbitals and states are effectively tuned via the introduction of electron-withdrawing groups. The HOMO is located primarily on the carbazolophane donor moiety, while the LUMO is distributed across the triazine acceptor and phenylene bridge. The HOMO levels of the two derivatives are expectedly significantly stabilized at $-5.91 \mathrm{eV}$ (CNCzpPhTRZ), and $-5.78 \mathrm{eV}$ ( $\mathbf{C F}_{3} \mathbf{C z p P h T R Z ) ~ c o m p a r e d ~ t o ~ t h a t ~ o f ~ t h e ~ p a r e n t ~ e m i t t e r ~ C z p P h T R Z ~}$ $(-5.54 \mathrm{eV})$ due to the presence of the electron-withdrawing cyano and trifluoromethyl groups, respectively. The more positive Hammett $\sigma_{\mathrm{p}}$ value for cyano (0.66) versus trifluoromethyl (0.54) explains the $0.13 \mathrm{eV}$ greater stabilization observed for the HOMO of CNCzpPhTRZ. The LUMO levels are somewhat less affected by substituting the carbazolophane at -2.08 and $-2.00 \mathrm{eV}$, respectively, for $\mathbf{C N C z p P h T R Z}$ and $\mathbf{C F}_{3} \mathbf{C z p P h T R Z}$ and deeper than that of CzpPhTRZ $(-1.88 \mathrm{eV})$. There is a corresponding increase in the energy of the $\mathrm{S}_{1}$ state from $3.12 \mathrm{eV}$ (CzpPhTRZ) to $3.27 \mathrm{eV}$ (CNCzpPhTRZ) and $3.23 \mathrm{eV}\left(\mathbf{C F}_{3} \mathbf{C z p P h T R Z )}\right.$. The triplet energies are unaffected by the substituents with $2.81 \mathrm{eV}$ (CzpPhTRZ), $2.96 \mathrm{eV}$ (CNCzpPhTRZ) and $2.92 \mathrm{eV}\left(\mathbf{C F}_{3} \mathbf{C z p P h T R Z}\right)$. The $\Delta E_{\mathrm{ST}}$ values of CNCzpPhTRZ (0.31 eV) and $\mathbf{C F}_{3}$ CzpPhTRZ (0.31 eV) are almost identical to that of CzpPhTRZ (0.30 eV), which suggests that these three molecules will be equally promising TADF emitters. The oscillator strengths, $f$, for the transition to the $\mathrm{S}_{1}$ state of CNCzpPhTRZ $(f=0.319)$ and $\mathbf{C F}_{3} \mathbf{C z p P h T R Z}(f=0.325)$ are slightly reduced compared to CzpPhTRZ ( $f=0.418)$, indicating a slightly slower radiative decay rate.

\section{Electrochemical studies}

Cyclic voltammetry (CV) and differential pulse voltammetry (DPV) measurements in dichloromethane (DCM) with tetra- $n$ butylammonium hexafluorophosphate $\left(\mathrm{TBAPF}_{6}\right)$ as the supporting electrolyte were used to infer the HOMO/LUMO levels of $\mathrm{CF}_{3} \mathrm{CzpPhTRZ}$ and CNCzpPhTRZ from the redox potentials. The resulting voltammograms are shown in Fig. S1 (ESI $\dagger$ ), and the data are summarized in Table 1. Both emitters possess similar irreversible oxidation potentials. The oxidation potential of $\mathrm{CF}_{3} \mathrm{CzpPhTRZ}$ is $1.30 \mathrm{~V} v \mathrm{v}$. SCE, and that of CNCzpPhTRZ is $1.34 \mathrm{~V} v s$. SCE (Fig. S1, ESI $\dagger$ ), which are each assigned to the oxidation of the carbazolophane (Czp) donor moieties, values that are anodically shifted relative to that of CzpPhTRZ $(1.14 \mathrm{~V}) .{ }^{18}$ The estimated HOMO levels are $-5.64 \mathrm{eV}$ and $-5.68 \mathrm{eV}$ for $\mathrm{CF}_{3} \mathrm{CzpPhTRZ}$ and CNCzpPhTRZ, respectively. These two HOMO levels are very similar, suggesting that the $\mathrm{CN}$ and $\mathrm{CF}_{3}$ have a similar electron-withdrawing ability in these compounds.

Further, the ionization potential was directly measured by UV ambient pressure photoemission spectroscopy (APS) and showed deeper levels of $6.05 \mathrm{eV}$ for $\mathrm{CF}_{3} \mathrm{CzpPhTRZ}$ and $5.93 \mathrm{eV}$ for CNCzpPhTRZ than those determined from the solution-state electrochemistry, this due in part to the different measurement environments (neat film for APS and DCM for DPV). These values align much more closely to the DFT calculated values (vide supra), although we note the calculations are in vacuo whereas the measurements are on solid films. The reduction 


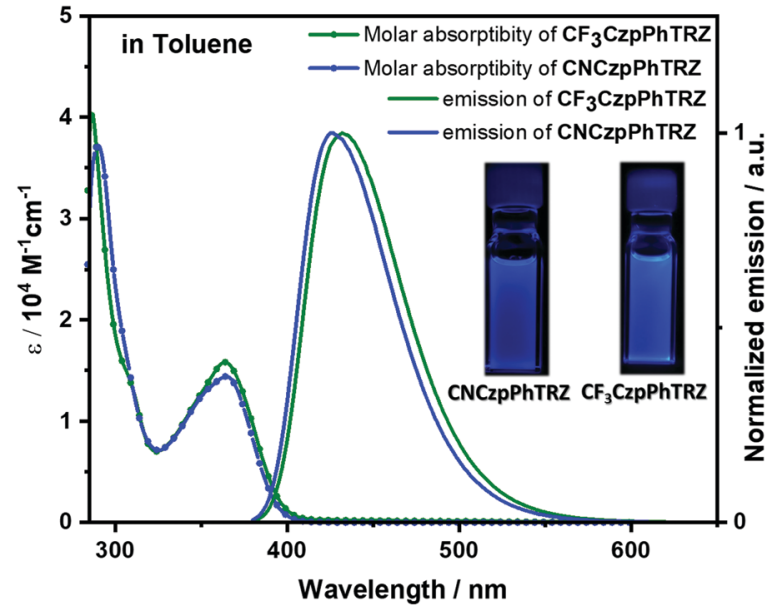

Fig. 3 Molar absorptivity and photoluminescence spectra of $\mathrm{CF}_{3} \mathbf{C z p P h T R Z}$ and CNCzpPhTRZ in toluene at $298 \mathrm{~K}\left(\lambda_{\text {exc }}=360 \mathrm{~nm}\right)$. Inset: photos of photoexcited solutions in toluene.

waves assigned to the reduction of the cyaphenine acceptor are quasi-reversible at $-1.67 \mathrm{~V} v s$. SCE. The reduction potentials are slightly shifted anodically compared to $E_{\text {red }}$ of $-1.78 \mathrm{~V}$ for CzpPhTRZ. ${ }^{18}$ The corresponding LUMO levels are $-2.68 \mathrm{~V}$ and $-2.67 \mathrm{~V}$ for $\mathrm{CF}_{3} \mathrm{CzpPhTRZ}$ and CNCzpPhTRZ, respectively.

\section{Solution-state photophysical studies}

Both molecules show similar absorption and photoexcitation spectra in dilute toluene (Fig. 3 and Fig. S3, ESI $\dagger$ ). The absorption bands of $\mathbf{C F}_{3}$ CzpPhTRZ at $363 \mathrm{~nm}$ and $\mathbf{C N C z p P h T R Z}$ at $365 \mathrm{~nm}$ are of similar intensities $\left(\varepsilon=1.6 \times 10^{4} v\right.$ s. $\left.1.4 \times 10^{4} \mathrm{M}^{-1} \mathrm{~cm}^{-1}\right)$ and are assigned to an intramolecular charge transfer (ICT) from the carbazolophane donor to the triazine acceptor. These CT bands are $c a .10 \mathrm{~nm}$ hypsochromically shifted compared to the CT band of the reference compound CzpPhTRZ. ${ }^{18}$

The photoluminescence (PL) spectra of both emitters in toluene are shown in Fig. 3. The PL maxima of $\mathbf{C F}_{3} \mathbf{C z p P h T R Z}$ at $432 \mathrm{~nm}$ and CNCzpPhTRZ at $426 \mathrm{~nm}$ are significantly blueshifted compared to that of the reference CzpPhTRZ emitter $\left(\lambda_{\mathrm{PL}}=470 \mathrm{~nm}\right)$. The emission spectra are unstructured, indicative of an excited state with a strong ICT character. The fullwidth-at-half maximum (FWHM) for CNCzpPhTRZ ( $0.36 \mathrm{eV})$ is slightly smaller than that of $\mathbf{C F}_{3} \mathbf{C z p P h T R Z}(0.41 \mathrm{eV})$. The PL quantum yield $\left(\Phi_{\mathrm{PL}}\right)$ values in degassed toluene are $80 \%$ for $\mathbf{C F}_{3}$ CzpPhTRZ and $73 \%$ for CNCzpPhTRZ, which decreased upon exposure to oxygen to $69 \%$ for $\mathbf{C F}_{3} \mathbf{C z p P h T R Z}$ and $61 \%$ for CNCzpPhTRZ. The $\Phi_{\mathrm{PL}}$ of both emitters in toluene is higher than that of the parent emitter $(70 \%$ in degassed toluene and $55 \%$ after exposure to oxygen). ${ }^{18}$ Triplets are sensitive to quenching by oxygen and so the lower $\Phi_{\mathrm{PL}}$ after exposure to oxygen shows that triplets play a role in the light emission process. ${ }^{23,24}$ The time-resolved PL decays of both compounds exhibited mono-exponential decay kinetics with PL lifetimes, $\tau$, of $5.47 \mathrm{~ns}$ and $4.87 \mathrm{~ns}$ for $\mathbf{C F}_{3}$ CzpPhTRZ and CNCzpPhTRZ, respectively (Fig. S4, ESI $\dagger$ ); no delayed emission in toluene was detected despite the oxygen sensitivity noted for the $\Phi_{\mathrm{PL}}$. Thus,

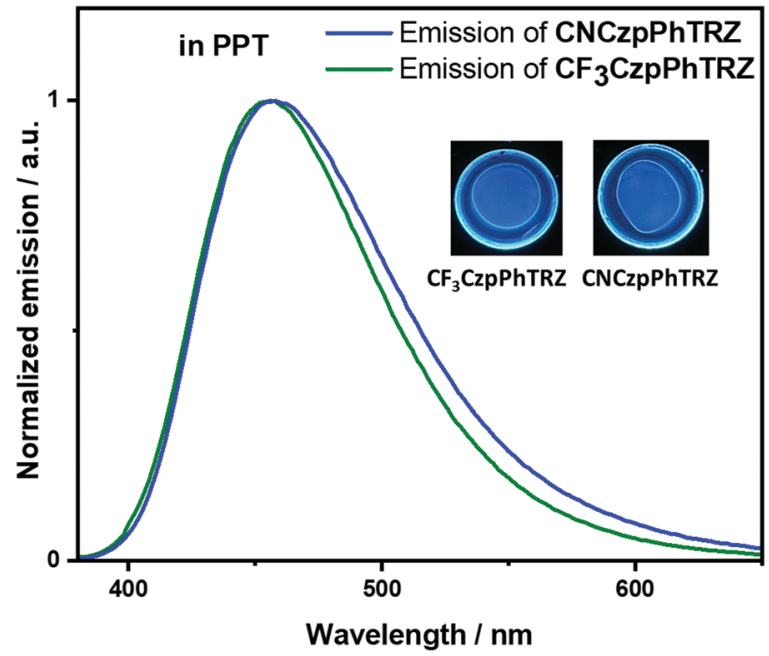

Fig. 4 Photoluminescence spectra of $\mathrm{CF}_{3} \mathrm{CzpPhTRZ}$ and CNCzpPhTRZ dispersed at $10 \mathrm{wt} \%$ in PPT matrix at $295 \mathrm{~K}\left(\lambda_{\mathrm{exc}}=360 \mathrm{~nm}\right)$.

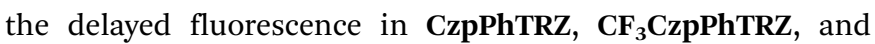
CNCzpPhTRZ in toluene is smaller than we can reliably detect.

\section{Photophysical properties in thin films}

Recognizing examples where there is little evidence for TADF in solution but that TADF is prevalent in the solid-state for compounds with relatively large calculated $\Delta E_{\mathrm{ST}}$ values, ${ }^{24,26}$ we next focused our attention on the photophysical properties of $\mathbf{C F}_{3} \mathbf{C z p P h T R Z}$ and $\mathbf{C N C z p P h T R Z}$ in doped thin films. Initially, a photophysical investigation was conducted on spincoated $10 \mathrm{wt} \%$ doped films in poly(methyl methacrylate) (PMMA) as the polarity of this host closely mimics that of toluene (PhMe). The absorption bands are of similar energy to those in PhMe, with the CT band observed at about $363 \mathrm{~nm}$ (Fig. S5, ESI $\dagger$ ). Both compounds showed the unstructured ICT-based emission at around $435 \mathrm{~nm}$, similar to that observed

Table 2 Photophysical properties of $\mathrm{CF}_{3} \mathrm{CzpPhTRZ}_{\mathrm{P}}$ and $\mathrm{CNCzpPhTRZ}^{\mathrm{a}}$

\begin{tabular}{lccll}
\hline Emitters & $\lambda_{\mathrm{PL}} / \mathrm{nm}$ & $\tau_{\mathrm{p}} / \mathrm{ns}$ & $\tau_{\mathrm{d}} / \mu \mathrm{s}$ & $\Phi_{\mathrm{PL}} / \%$ \\
\hline In toluene $^{b}$ & & & & \\
CF $_{3}$ CzpPhTRZ & 432 & 5.47 & - & $80(69)$ \\
CNCzpPhTRZ & 426 & 4.87 & - & $73(61)$ \\
10 wt\% doped in PMMA & & & & \\
CF $_{3}$ CzpPhTRZ & 436 & 6.84 & 151.4 & $63(61)$ \\
CNCzpPhTRZ $^{c}$ & 435 & 7.32 & 132.1 & $62(59)$ \\
10 wt\% doped in PPT & & & & \\
CF $_{3}$ CzpPhTRZ & 456 & 6.63 & 158.3 & $70(65)$ \\
CNCzpPhTRZ & 458 & 6.75 & 135.0 & $65(60)$
\end{tabular}

${ }^{a}$ At $298 \mathrm{~K} .^{b}$ Quinine sulfate $(0.5 \mathrm{M})$ in $\mathrm{H}_{2} \mathrm{SO}_{4}$ (aq.) was used as the reference $\left(\Phi_{\mathrm{PL}}: 54.6 \%, \lambda_{\text {exc }}=360 \mathrm{~nm}\right) .{ }^{25}$ Values quoted are in degassed solutions, which were prepared by three freeze-pump-thaw cycles. The values in parentheses are in the presence of $\mathrm{O}_{2} \cdot{ }^{c}$ Thin films were prepared by spin-coating $10 \mathrm{wt} \%$ doped samples in PMMA and PPT. Steady-state and time-resolved emission spectra were recorded at $298 \mathrm{~K}$ under an $\mathrm{O}_{2}$-free atmosphere $\left(\lambda_{\text {exc }}=360 \mathrm{~nm}\right.$ for steady-state and $\lambda_{\text {exc }}=379 \mathrm{~nm}$ for time-resolved emission). Photoluminescence quantum yields of thin films were determined using an integrating sphere $\left(\lambda_{\text {exc }}=300 \mathrm{~nm}\right.$ or $\left.360 \mathrm{~nm}\right)$ under $\mathrm{N}_{2}$ atmosphere at $298 \mathrm{~K}$. The values in parentheses are in the presence of $\mathrm{O}_{2}$. 

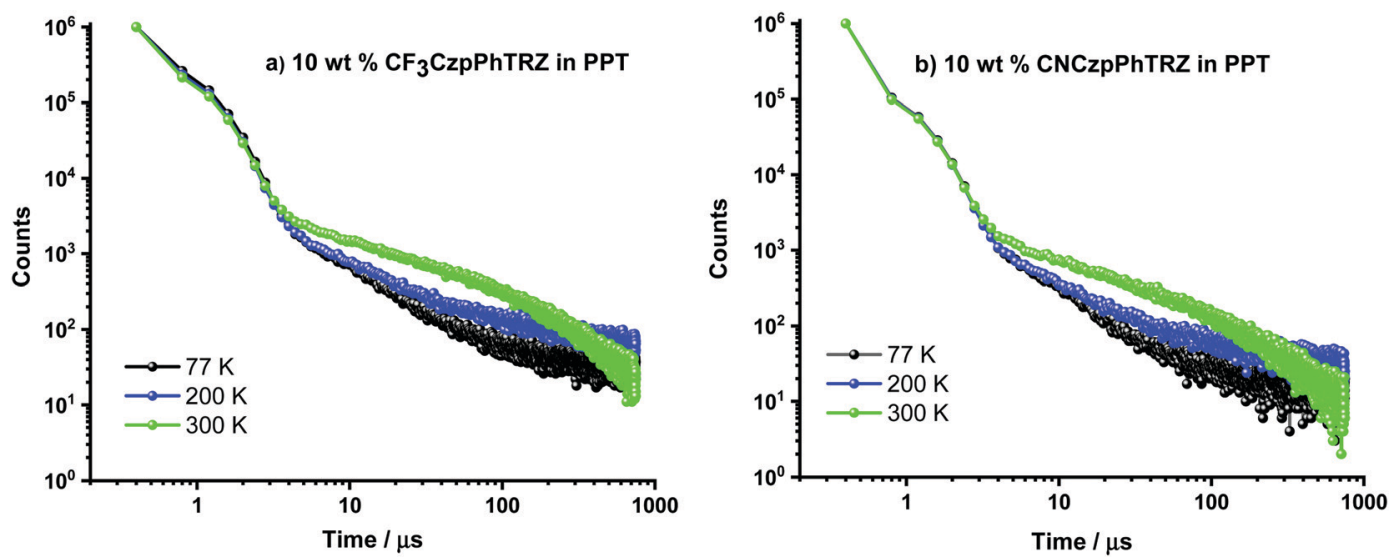

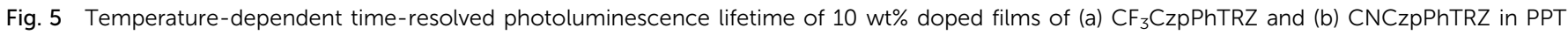
$\left(\lambda_{\mathrm{exc}}=379 \mathrm{~nm}\right)$.

in PhMe (Fig. S5, ESI $\dagger$ ). The PL spectra are blue-shifted by $c a$. $30 \mathrm{~nm}$ compared to that of the parent emitter CzpPhTRZ. The $\Phi_{\mathrm{PL}}$ values are modestly decreased relative to those in solution at $63 \%$ and $62 \%$ for $\mathbf{C F}_{3}$ CzpPhTRZ and CNCzpPhTRZ, respectively, under $\mathrm{N}_{2}$ atmosphere, likely reflective of some aggregation-caused quenching. Biexponential decay kinetics were observed in the time-resolved decays with $\tau_{\mathrm{p}}$ values of $6.84 \mathrm{~ns}$ and $7.32 \mathrm{~ns}$ and $\tau_{\mathrm{d}}$ values of 151.4 and $132.1 \mu \mathrm{s}$ for $\mathbf{C F}_{3}$ CzpPhTRZ and CNCzpPhTRZ, respectively (Fig. S6, ESI $\dagger$ ). We measured prompt fluorescence and phosphorescence spectra of both emitters in PMMA films at $77 \mathrm{~K}$. The energy difference, taken from the onsets of these spectra, provides $\Delta E_{\mathrm{ST}}$ values of 0.27 and $0.30 \mathrm{eV}$ for $\mathbf{C F}_{3} \mathbf{C z p P h T R Z}$ and CNCzpPhTRZ, respectively. These data are consistent with TADF being operative for the emitters in PMMA films. We then investigated the photophysical behavior of the both compounds in suitably high triplet energy and deep HOMO level OLED-relevant hosts such as bis[2-(diphenylphosphino)phenyl] ether oxide (DPEPO, $\left.E_{\mathrm{T}}=3.0 \mathrm{eV}, E_{\mathrm{HOMO}}=-6.3 \mathrm{eV}\right)^{27,28}$ and 2,8-bis(diphenyl-phosphoryl)dibenzo[ $[b, d]$ thiophene (PPT, $\left.E_{\mathrm{T}}=3.1 \mathrm{eV}, E_{\mathrm{HOMO}}=-6.7 \mathrm{eV}\right){ }^{29}$ A concentration study of both emitters revealed that the $\Phi_{\mathrm{PL}}$ was highest in $10 \mathrm{wt} \%$ doped films in PPT (Table S2, ESI $\dagger$ ). The $\Phi_{\mathrm{PL}}$ of $10 \mathrm{wt} \% \mathbf{C F}_{3} \mathbf{C z p P h T R Z}$ doped in PPT is $70 \%$, while in DPEPO at the same doping concentration, it is $53 \%$. Similarly, the $\Phi_{\mathrm{PL}}$ of $10 \mathrm{wt} \%$ CNCzpPhTRZ doped in PPT is $65 \%$, and in the corresponding DPEPO film, it is $52 \%$. By contrast, the parent emitter CzpPhTRZ showed $\Phi_{\mathrm{PL}}$ of $69 \%$ in the $10 \mathrm{wt} \%$ doped DPEPO film and only $55 \%$ in the $10 \mathrm{wt} \%$ doped PPT film. ${ }^{18}$ The absorption spectra in these host matrices are very similar to those in PMMA (Fig. S7, ESI†). However, $\lambda_{\mathrm{PL}}$ of both emitters are about $20 \mathrm{~nm}$ red-shifted at around $456 \mathrm{~nm}$ in these two host matrices, suggesting stronger aggregation ${ }^{30,31}$ (Fig. 4 and Fig. S8 (ESI $\dagger$ ) and Table 2). The emission of both emitters is expectedly blue-shifted $(\sim 25 \mathrm{~nm})$ in comparison to parent emitter CzpPhTRZ $\left(\lambda_{\mathrm{PL}}=482 \mathrm{~nm}\right.$ in $10 \mathrm{wt} \%$ doped films in DPEPO). ${ }^{18}$ The time-resolved PL decays in PPT show a nanosecond prompt emission and microsecond delayed emission at room temperature with comparable values to those measured in PMMA. The $\tau_{\mathrm{d}}$ values of the $10 \mathrm{wt} \%$ doped PPT films are $158.3 \mu \mathrm{s}$ for $\mathbf{C F}_{3}$ CzpPhTRZ and $135.0 \mu$ s for CNCzpPhTRZ, which is significantly

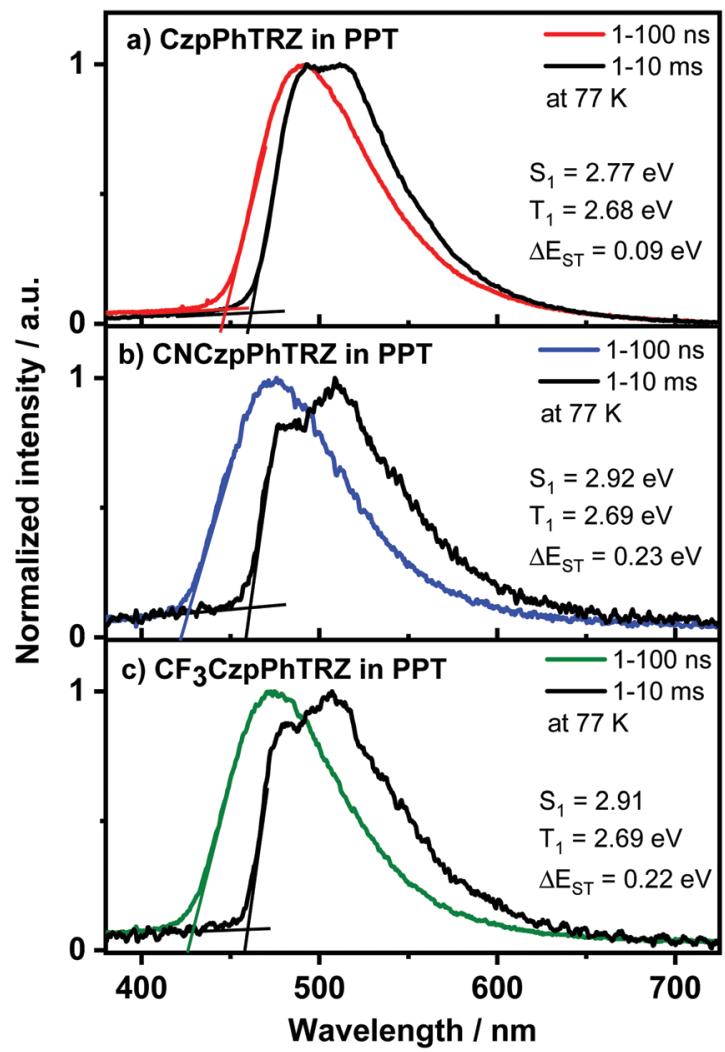

Fig. $677 \mathrm{~K}$ prompt $\mathrm{PL}$ and phosphorescence spectra measurement of 10 wt\% (a) CzpPhTRZ (b) $\mathrm{CF}_{3}$ CzpPhTRZ and (c) CNCzpPhTRZ doped in PPT host $\left(\lambda_{\text {exc }}=343 \mathrm{~nm}\right.$ ), the $\Delta E_{\mathrm{ST}}$ value is taken from the onset value difference between the $77 \mathrm{~K}$ prompt fluorescence and phosphorescence spectra.

longer than that measured for parent emitter CzpPhTRZ in the $10 \mathrm{wt} \%$ DPEPO film $\left(\tau_{\mathrm{d}}=65 \mu \mathrm{s}\right)$. The temperature-dependent timeresolved PL decays in PPT are shown in Fig. 5. The prompt emission is insensitive to temperature, while the delayed emission is thermally activated, a behavior consistent with TADF.

We next prepared $10 \mathrm{wt} \%$ doped films of each emitter in PPT as a host matrix. As shown in Fig. 6, the $S_{1}$ levels of 

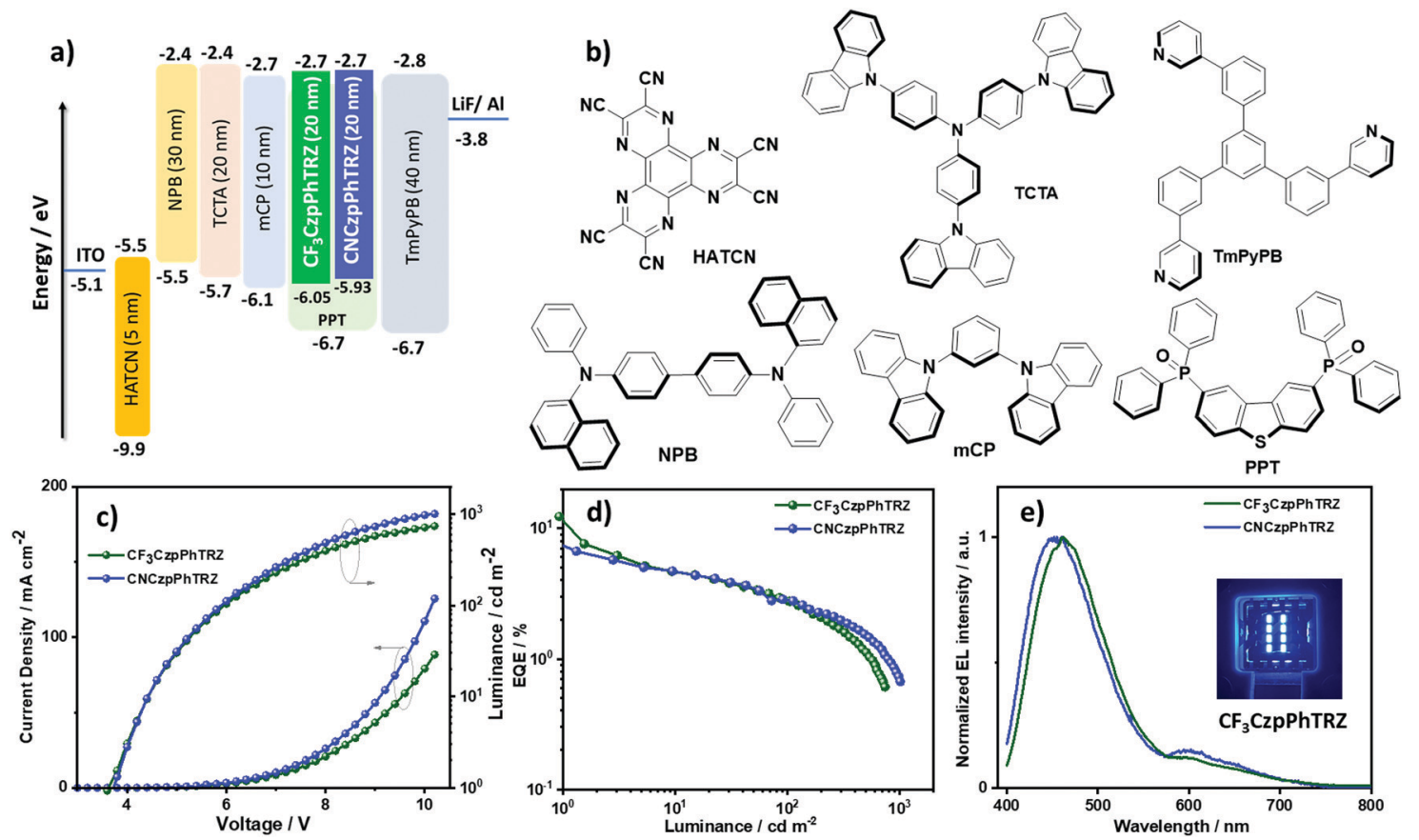

Fig. 7 (a) Energy level diagram of materials employed in the devices; (b) molecular structure of materials used in the devices; (c) current density and luminescence versus voltage characteristics for the devices; (d) external quantum efficiency versus luminescence curves for the devices; (e) electroluminescence spectra of the device of $\mathrm{CF}_{3} \mathrm{CzpPhTRZ}$ and $C N C z p P h T R Z$, the inset is the electroluminescence of $\mathrm{CF}_{3} \mathrm{CzpPhTRZ}$.

CF $_{3}$ CzpPhTRZ $\left(\mathrm{S}_{1}=2.92 \mathrm{eV}\right)$ and CNCzpPhTRZ $\left(\mathrm{S}_{1}=2.91\right)$ are very similar and at higher energy than that of the parent emitter CzpPhTRZ $\left(S_{1}=2.77 \mathrm{eV}\right)$; interestingly, the $S_{1}$ level of CzpPhTRZ in DPEPO is $2.89 \mathrm{eV}$. The $\mathrm{S}_{1}$ energies in PPT are only slightly lower in energy than those determined in PMMA $\left(S_{1}=3.0 \mathrm{eV}\right)$, Fig. S9 $(\mathrm{ESI} \dagger)$. The $\mathrm{T}_{1}$ levels remain largely the same, regardless of the nature of the host medium or the structure of the emitter, and are of similar magnitude to their corresponding triphenyl triazine acceptor segments in toluene, ${ }^{32}$ indicating that the $\mathrm{T}_{1}$ state is locally excited $\left({ }^{3} \mathrm{LE}\right)$ character. The $\mathrm{T}_{1}$ levels for $\mathbf{C F}_{3}$ CzpPhTRZ, CNCzpPhTRZ and CzpPhTRZ are all around 2.69 eV in PPT (Fig. 6) and closely resembles those measured in PMMA at $2.73 \mathrm{eV}$ (Fig. S9, ESI $\dagger$ ) and the reported triplet energy of CzpPhTRZ in DPEPO $(2.73 \mathrm{eV}) .{ }^{18}$ The corresponding $\Delta E_{\mathrm{ST}}$ values are $0.22 \mathrm{eV}$ for $\mathbf{C F}_{3}$ CzpPhTRZ, $0.23 \mathrm{eV}$ for CNCzpPhTRZ, and $0.09 \mathrm{eV}$ for CzpPhTRZ in PPT (Fig. 6 and Table 2); the reported $\Delta E_{\mathrm{ST}}$ of $10 \mathrm{wt} \%$ CzpPhTRZ doped in DPEPO is $0.16 \mathrm{eV}^{18}$ The larger $\Delta E_{\mathrm{ST}}$ values for $\mathbf{C F}_{3} \mathbf{C z p P h T R Z}$ and CNCzpPhTRZ explain the longer delayed lifetimes and less efficient RISC, which can be rationalized due to the weaker electron-donor leading to a larger overlap integral.

\section{Device characterization}

Based on the promising photophysical properties of $\mathbf{C F}_{3}$ CzpPhTRZ and CNCzpPhTRZ in PPT films, we fabricated thermally-evaporated multilayer bottom-emitting OLEDs. The OLED stack architecture is shown in Fig. 7a and consisted of: indium tin oxide (ITO)/1,4,5,8,9,11-hexaazatriphenyleneheacarbonitrile (HATCN) (5 nm) $/ N, N^{\prime}-\operatorname{di}(1-$ naphthyl)- $N$, $N^{\prime}$-diphenyl-(1,1'-biphenyl)-4,4'-diamine (NPB) (30 $\left.\mathrm{nm}\right) /$ tris(4-carbazoyl-9-ylphenyl)amine (TCTA) $(20 \mathrm{~nm}) / 1,3-\mathrm{bis}(N$ carbazolyl)benzene (mCP) (10 nm)/emissive layer $(20 \mathrm{~nm}) / 1,3$, 5-tri[(3-pyridyl)-phen-3-yl]benzene (TmPyPB) (40 nm)/LiF $(0.5 \mathrm{~nm}) /$ $\mathrm{Al}(100 \mathrm{~nm})$, where HATCN plays the role of hole-injection layer (HIL), NPB and TCTA were employed as hole-transport layer (HTL), mCP acts as an electron/exciton-blocker layer (EBL) and TmPyPB plays the role of an electron-transport layer (ETL) and hole-blocking layer (HBL) due to its deep HOMO $(-6.7 \mathrm{eV}) ;^{33} \mathrm{LiF}$ acts as electroninjection layer (EIL) by modifying the work function of the aluminum cathode. The molecular structures of the materials used in these OLEDs are shown in Fig. 7b. The emission layer (EML) comprises 10 wt $\%$ of $\mathbf{C F}_{3}$ CzpPhTRZ or 10 wt $\%$ CNCzpPhTRZ doped into PPT. The electroluminescence properties of the OLEDS are summarized in Table 3, and current density-voltage-brightness

Table 3 Electroluminescence data for the devices

\begin{tabular}{|c|c|c|c|c|c|c|c|}
\hline Emitter & Host & $V_{\text {on }}{ }^{a} / \mathrm{V}$ & $\lambda_{\mathrm{EL}}^{b} / \mathrm{nm}$ & $\mathrm{CE}^{c} / \mathrm{cd} \mathrm{A}^{-1}$ & $\mathrm{PE}_{\max } / \operatorname{lm~W^{-1}}$ & $\mathrm{EQE}^{c} / \%$ & $\mathrm{CIE}^{d} / x, y$ \\
\hline CF $_{3}$ CzpPhTRZ (10 wt\%) & PPT & 3.7 & 460 & 16.8 & 13.7 & $11.6 / 2.7$ & $0.186,0.200$ \\
\hline CNCzpPhTRZ (10 wt\%) & PPT & 3.7 & 456 & 9.1 & 7.5 & $7.4 / 2.7$ & $0.194,0.182$ \\
\hline
\end{tabular}

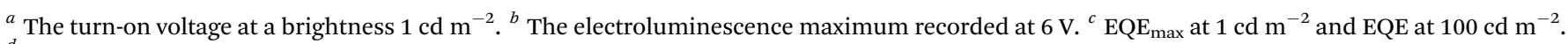

${ }^{d}$ The CIE coordinates were recorded at $7 \mathrm{~V}$. 
$(J-V-L)$ curves, EQE-luminance curves and electroluminescence spectra (EL) are given in Fig. 7c-e. The turn-on voltage of the devices is $c a .3 .7 \mathrm{~V}$ at $1 \mathrm{~cd} \mathrm{~m}^{-2}$. The maximum external quantum efficiency ( $\mathrm{EQE}_{\max }$ ) of the $\mathbf{C F}_{\mathbf{3}} \mathbf{C z p P h T R Z}$ and $\mathbf{C N C z p P h T R Z}$ based devices at $1 \mathrm{~cd} \mathrm{~m}^{-2}$ and is $11.6 \%$ and $7.4 \%$, respectively, with a current efficiency $(\mathrm{CE})=16.8 \mathrm{~cd} \mathrm{~A}^{-1}$ and $9.08 \mathrm{~cd} \mathrm{~A}^{-1}$ and a power efficiency $(\mathrm{PE})=13.7 \mathrm{~lm} \mathrm{~W}^{-1}$ and $7.5 \mathrm{~lm} \mathrm{~W}^{-1}$, respectively (Fig. S10 and S11, ESI $\dagger$ ). The devices with both emitters show high-efficiency roll-off with EQEs at $100 \mathrm{~cd} \mathrm{~m}^{-2}$ at only $2.7 \%$, due in part to inefficient harvesting triplet exciton because of the high triplet lifetime of both emitters. As expected, the optimized $\mathbf{C F}_{\mathbf{3}} \mathbf{C z p P h T R Z}$ and CNCzpPhTRZ based devices display a blue-shifted emission at around $460 \mathrm{~nm}$ compared to the previously reported OLED with CzpPhTRZ $\left(\lambda_{\mathrm{EL}}=480 \mathrm{~nm}\right)$, consistent with the trend of their film PL emission (Fig. 7e). The corresponding CIE coordinates are (0.186, 0.200), and (0.194, 0.182) for $\mathbf{C F}_{3}$ CzpPhTRZ and CNCzpPhTRZ, respectively.

Surprisingly, we observed spectral changes of the electroluminescence in both devices with an emission band in the region of $600 \mathrm{~nm}$ developing as the device was run whereas upon photoexcitation, we did not observe any emission around $600 \mathrm{~nm}$. We ascribe this new feature in the EL spectrum to degradation of the emitter during device operation. We also observed emission at around $600 \mathrm{~nm}$ from the decomposed residue isolated from the sample boat after gradient sublimation under vacuum, which is very similar to the EL feature above $600 \mathrm{~nm}$ (Fig. S12, ESI $\dagger$ ) and may be attributed to aggregate formation. ${ }^{34}$

\section{Conclusions}

We developed two new TADF emitters containing a substituted carbazolophane (Czp) donor unit (indolo[2.2]paracyclophane) containing the electron-withdrawing groups cyano $(\mathbf{C N})$ and trifluoromethyl $\left(\mathbf{C F}_{3}\right)$ to obtain the deep and pure blue emission. Both emitters show high photoluminescence quantum yield. The $\Delta E_{\mathrm{ST}}$ is $0.23 \mathrm{eV}$ for $\mathbf{C F}_{3}$ CzpPhTRZ and $0.22 \mathrm{eV}$ for CNCzpPhTRZ with long-delayed lifetime of $158.3 \mu \mathrm{s}$ for CF $_{3}$ CzpPhTRZ and $135.0 \mu$ s for CNCzpPhTRZ in PPT host shows TADF behavior. Blue OLEDs were fabricated with these new TADF emitters showing an $\mathrm{EQE}_{\max }$ of $7.4 \%$ for CNCzpPhTRZ and $\mathbf{1 1 . 6 \%}$ for $\mathbf{C F}_{3} \mathbf{C z p P h T R Z}$ at electroluminescence wavelength around $460 \mathrm{~nm}$ with CIE coordinates of (0.194, 0.182) for the device with $\mathbf{C F}_{3}$ CzpPhTRZ and (0.186, 0.200) for the device with $\mathbf{C F}_{3}$ CzpPhTRZ. We observed an unexpected emission band around $600 \mathrm{~nm}$ in OLEDs upon electrical excitation, which we attributed to degradation of the emitter.

\section{Conflicts of interest}

There are no conflicts to declare.

\section{Acknowledgements}

AKG is grateful to the Royal Society for Newton International Fellowship NF171163. We acknowledge support from the Engineering and Physical Sciences Research Council of the UK (grants EP/P010482/1 and EP/L017008/1). The German Research Foundation (formally Deutsche Forschungsgemeinschaft DFG) in the framework of SFB1176 Cooperative Research Centre "Molecular Structuring of Soft Matter" (CRC1176, A4, B3, C2, C6) and the cluster 3D Matter made to order all funded under Germany's Excellence Strategy 2082/1-390761711 are acknowledged for financial contributions.

\section{References}

1 H. Uoyama, K. Goushi, K. Shizu, H. Nomura and C. Adachi, Highly efficient organic light-emitting diodes from delayed fluorescence, Nature, 2012, 492(7428), 234-238, DOI: 10.1038/nature11687.

2 Z. Yang, Z. Mao, Z. Xie, Y. Zhang, S. Liu, J. Zhao, J. Xu, Z. Chi and M. P. Aldred, Recent advances in organic thermally activated delayed fluorescence materials, Chem. Soc. Rev., 2017, 46(3), 915-1016, DOI: 10.1039/c6cs00368k.

3 M. Y. Wong and E. Zysman-Colman, Purely organic thermally activated delayed fluorescence materials for organic light-emitting diodes, Adv. Mater., 2017, 29(22), 1605444, DOI: 10.1002/adma.201605444.

4 G. Hong, X. Gan, C. Leonhardt, Z. Zhang, J. Seibert, J. M. Busch and S. Bräse, A brief history of OLEDs-emitter development and industry milestones, Adv. Mater., 2021, 33(9), DOI: 10.1002/adma.202005630.

5 T. Hatakeyama, K. Shiren, K. Nakajima, S. Nomura, S. Nakatsuka, K. Kinoshita, J. Ni, Y. Ono and T. Ikuta, Ultrapure blue thermally activated delayed fluorescence molecules: Efficient HOMO-LUMO separation by the multiple resonance effect, Adv. Mater., 2016, 28(14), 2777-2781, DOI: $10.1002 /$ adma.201505491.

6 L. Gan, Z. Xu, Z. Wang, B. Li, W. Li, X. Cai, K. Liu, Q. Liang and $\mathrm{S}$. J. Su, Utilizing a spiro TADF moiety as a functional electron donor in TADF molecular design toward efficient "multichannel" reverse intersystem crossing, Adv. Funct. Mater., 2019, 29(20), 1-8, DOI: 10.1002/adfm.201808088.

7 M. Sarma and K. T. Wong, Exciplex: An intermolecular charge-transfer approach for TADF, ACS Appl. Mater. Interfaces, 2018, 10(23), 19279-19304, DOI: 10.1021/acsami. $7 \mathrm{~b} 18318$.

8 A. K. Gupta, W. Li, A. Ruseckas, C. Lian, C. L. CarpenterWarren, D. B. Cordes, A. M. Z. Slawin, D. Jacquemin, I. D. W. Samuel and E. Zysman-Colman, Thermally activated delayed fluorescence emitters with intramolecular proton transfer for high luminance solution-processed organic light-emitting diodes, ACS Appl. Mater. Interfaces, 2021, 13(13), 15459-15474, DOI: 10.1021/acsami.1c02248.

9 E. Spuling, N. Sharma, I. D. W. Samuel, E. Zysman-Colman and S. Bräse, (Deep) blue through-space conjugated TADF 
emitters based on [2.2]paracyclophanes, Chem. Commun., 2018, 54(67), 9278-9281, DOI: 10.1039/c8cc04594a.

10 Z. Hassan, E. Spuling, D. M. Knoll and S. Bräse, Regioselective functionalization of [2.2]paracyclophanes: Recent synthetic progress and perspectives, Angew. Chem., Int. Ed., 2020, 59(6), 2156-2170, DOI: 10.1002/anie. 201904863.

11 Z. Hassan, E. Spuling, D. M. Knoll, J. Lahann and S. Bräse, Planar Chiral [2.2]Paracyclophanes: From Synthetic Curiosity to Applications in Asymmetric Synthesis and Materials, Chem. Soc. Rev., 2018, 47(18), 6947-6963, DOI: 10.1039/ c7cs00803a.

12 J. Zyss, I. Ledoux, S. Volkov, V. Chernyak, S. Mukamel, G. P. Bartholomew and G. C. Bazan, Through-space charge transfer and nonlinear optical properties of substituted paracyclophane, J. Am. Chem. Soc., 2000, 122(48), 11956-11962, DOI: 10.1021/ja0022526.

13 A. Marrocchi, I. Tomasi and L. Vaccaro, Organic small molecules for photonics and electronics from the [2.2]paracyclophane scaffold, Isr. J. Chem., 2012, 52(1-2), 41-52, DOI: 10.1002/ijch.201100091.

14 D. J. Cram and J. M. Cram, Cyclophane chemistry: Bent and battered benzene rings, Acc. Chem. Res., 1971, 4(6), 204-213, DOI: 10.1021/ar50042a003.

15 Y. Morisaki, M. Gon, T. Sasamori, N. Tokitoh and Y. Chujo, Planar chiral tetrasubstituted [2.2]paracyclophane: Optical resolution and functionalization, J. Am. Chem. Soc., 2014, 136(9), 3350-3353, DOI: 10.1021/ja412197j.

16 M. Y. Zhang, Z. Y. Li, B. Lu, Y. Wang, Y. D. Ma and C. H. Zhao, Solid-state emissive triarylborane-based [2.2]paracyclophanes displaying circularly polarized luminescence and thermally activated delayed fluorescence, $\mathrm{Org}$. Lett., 2018, 20(21), 6868-6871, DOI: 10.1021/acs.orglett. 8 b02995.

17 M. Y. Zhang, X. Liang, D. N. Ni, D. H. Liu, Q. Peng and C. H. Zhao, 2-(Dimesitylboryl)phenyl-substituted [2.2]paracyclophanes featuring intense and sign-invertible circularly polarized luminescence, Org. Lett., 2021, 23(1), 2-7, DOI: 10.1021/acs.orglett.0c02463.

18 N. Sharma, E. Spuling, C. M. Mattern, W. Li, O. Fuhr, Y. Tsuchiya, C. Adachi, S. Bräse, I. D. W. Samuel and E. Zysman-Colman, Turn on of sky-blue thermally activated delayed fluorescence and circularly polarized luminescence (cpl): Via increased torsion by a bulky carbazolophane donor, Chem. Sci., 2019, 10(27), 6689-6696, DOI: 10.1039/ c9sc01821b.

19 C. Liao, Y. Zhang, S. Ye and W. Zheng, Planar chiral [2.2]paracyclophane-based thermally activated delayed fluorescent materials for circularly polarized electroluminescence, ACS Appl. Mater. Interfaces, 2021, 1c04779, DOI: 10.1021/acsami.1c04779.

20 M. Moral, L. Muccioli, W. J. Son, Y. Olivier and J. C. SanchoGarcia, Theoretical rationalization of the singlet-triplet gap in oleds materials: Impact of charge-transfer character, J. Chem. Theory Comput., 2015, 11(1), 168-177, DOI: $10.1021 /$ ct500957s.
21 N. G. Connelly and W. E. Geiger, Chemical redox agents for organometallic chemistry, Chem. Rev., 1996, 96(2), 877-910, DOI: 10.1021/cr940053x.

22 C. M. Cardona, W. Li, A. E. Kaifer, D. Stockdale and G. C. Bazan, Electrochemical considerations for determining absolute frontier orbital energy levels of conjugated polymers for solar cell applications, Adv. Mater., 2011, 23(20), 2367-2371, DOI: 10.1002/adma.201004554.

23 H. Tanaka, K. Shizu, H. Miyazaki and C. Adachi, Efficient green thermally activated delayed fluorescence (TADF) from a phenoxazine-triphenyltriazine (PXZ-TRZ) derivative, Chem. Commun., 2012, 48(93), 11392-11394, DOI: 10.1039/ c2cc36237f.

24 M. Y. Wong, S. Krotkus, G. Copley, W. Li, C. Murawski, D. Hall, G. J. Hedley, M. Jaricot, D. B. Cordes, A. M. Z. Slawin, Y. Olivier, D. Beljonne, L. Muccioli, M. Moral, J. C. Sancho-Garcia, M. C. Gather, I. D. W. Samuel and E. Zysman-Colman, Deep-blue oxadiazole-containing thermally activated delayed fluorescence emitters for organic light-emitting diodes, ACS Appl. Mater. Interfaces, 2018, 10(39), 33360-33372, DOI: 10.1021/acsami.8b11136.

25 A. M. Brouwer, Standards for photoluminescence quantum yield measurements in solution (IUPAC Technical Report), Pure Appl. Chem., 2011, 83(12), 2213-2228, DOI: 10.1351/ PAC-REP-10-09-31.

26 W. Li, Z. Li, C. Si, M. Y. Wong, K. Jinnai, A. K. Gupta, R. Kabe, C. Adachi, W. Huang, E. Zysman-Colman and I. D. W. Samuel, Organic long-persistent luminescence from a thermally activated delayed fluorescence compound, Adv. Mater., 2020, 32(45), 1-9, DOI: 10.1002/ adma.202003911.

27 Q. Zhang, T. Komino, S. Huang, S. Matsunami, K. Goushi and C. Adachi, Triplet exciton confinement in green organic light-emitting diodes containing luminescent chargetransfer $\mathrm{Cu}(\mathrm{I})$ complexes, Adv. Funct. Mater., 2012, 22(11), 2327-2336, DOI: 10.1002/adfm.201101907.

28 C. Han, Y. Zhao, H. Xu, J. Chen, Z. Deng, D. Ma, Q. Li and P. Yan, A simple phosphine-oxide host with a multiinsulating structure: High triplet energy level for efficient blue electrophosphorescence, Chem. - Eur. J., 2011, 17(21), 5800-5803, DOI: 10.1002/chem.201100254.

29 J. I. Nishide, H. Nakanotani, Y. Hiraga and C. Adachi, Highefficiency white organic light-emitting diodes using thermally activated delayed fluorescence, Appl. Phys. Lett., 2014, 104(23), 1-6, DOI: 10.1063/1.4882456.

30 K. Stavrou, L. G. Franca and A. P. Monkman, Photophysics of TADF guest-host systems: introducing the idea of hosting potential, ACS Appl. Electron. Mater., 2020, 2(9), 2868-2881, DOI: 10.1021/acsaelm.0c00514.

31 P. Imbrasas, R. Lygaitis, P. Kleine, R. Scholz, C. Hänisch, S. Buchholtz, K. Ortstein, F. Talnack, S. C. B. Mannsfeld, S. Lenk and S. Reineke, Dimers or solid-state solvation? Intermolecular effects of multiple donor-acceptor thermally activated delayed fluorescence emitter determining organic light-emitting diode performance, Adv. Opt. Mater., 2021, 2002153, 1-11, DOI: 10.1002/adom.202002153. 
32 S. Kumar, P. Rajamalli, D. B. Cordes, A. M. Z. Slawin and E. Zysman-Colman, Highly fluorescent emitters based on triphenylamine- $\pi$-triazine (D- $\pi$-A) System: Effect of extended conjugation on singlet-triplet energy gap, Asian J. Org. Chem., 2020, 9(9), 1277-1285, DOI: 10.1002/ajoc.20200 0165.

33 S. J. Su, T. Chiba, T. Takeda and J. Kido, Pyridine-containing triphenylbenzene derivatives with high electron mobility for highly efficient phosphorescent OLEDs, Adv. Mater., 2008, 20(11), 2125-2130, DOI: 10.1002/adma.200701730.

34 M. K. Etherington, N. A. Kukhta, H. F. Higginbotham, A. Danos, A. N. Bismillah, D. R. Graves, P. R. Mcgonigal, N. Haase, A. Morherr, A. S. Batsanov, P. Christof, V. Bhalla, M. R. Bryce and A. P. Monkman, Persistent dimer emission in thermally activated delayed fluorescence materials, J. Phys. Chem. C, 2019, 123, 11109-11117, DOI: 10.1021/acs.jpcc.9b01458. 